\title{
Predicting Biomass Char Yield from High Heating Rate Devolatilization using Chemometrics
}

\author{
Leth-Espensen, Anna; Glarborg, Peter; Jensen, Peter Arendt
}

Published in:

Energy and Fuels

Link to article, DOI:

10.1021/acs.energyfuels.8b02073

Publication date:

2018

Document Version

Peer reviewed version

Link back to DTU Orbit

Citation (APA):

Leth-Espensen, A., Glarborg, P., \& Jensen, P. A. (2018). Predicting Biomass Char Yield from High Heating Rate Devolatilization using Chemometrics. Energy and Fuels, 32(9), 9572-9580.

https://doi.org/10.1021/acs.energyfuels.8b02073

\section{General rights}

Copyright and moral rights for the publications made accessible in the public portal are retained by the authors and/or other copyright owners and it is a condition of accessing publications that users recognise and abide by the legal requirements associated with these rights.

- Users may download and print one copy of any publication from the public portal for the purpose of private study or research.

- You may not further distribute the material or use it for any profit-making activity or commercial gain

- You may freely distribute the URL identifying the publication in the public portal

If you believe that this document breaches copyright please contact us providing details, and we will remove access to the work immediately and investigate your claim. 


\title{
energy fuels:
}

Subscriber access provided by DTU Library

\section{Biofuels and Biomass}

\section{Predicting Biomass Char Yield from High Heating Rate Devolatilization using Chemometrics}

\author{
Anna Leth-Espensen, Peter Glarborg, and Peter Arendt Jensen
}

Energy Fuels, Just Accepted Manuscript • DOI: 10.1021/acs.energyfuels.8b02073 • Publication Date (Web): 09 Aug 2018

Downloaded from http://pubs.acs.org on August 13, 2018

\section{Just Accepted}

"Just Accepted" manuscripts have been peer-reviewed and accepted for publication. They are posted online prior to technical editing, formatting for publication and author proofing. The American Chemical Society provides "Just Accepted" as a service to the research community to expedite the dissemination of scientific material as soon as possible after acceptance. "Just Accepted" manuscripts appear in full in PDF format accompanied by an HTML abstract. "Just Accepted" manuscripts have been fully peer reviewed, but should not be considered the official version of record. They are citable by the Digital Object Identifier (DOI®). "Just Accepted" is an optional service offered to authors. Therefore, the "Just Accepted" Web site may not include all articles that will be published in the journal. After a manuscript is technically edited and formatted, it will be removed from the "Just Accepted" Web site and published as an ASAP article. Note that technical editing may introduce minor changes to the manuscript text and/or graphics which could affect content, and all legal disclaimers and ethical guidelines that apply to the journal pertain. ACS cannot be held responsible for errors or consequences arising from the use of information contained in these "Just Accepted" manuscripts. 
Predicting Biomass Char Yield from High Heating Rate Devolatilization using Chemometrics

\author{
Anna Leth-Espensen, Peter Glarborg, and Peter Arendt Jensen* \\ Technical University of Denmark, Department of Chemical and Biochemical Engineering, \\ Søltofts Plads 229, 2800 Kgs. Lyngby, Denmark \\ E-mail: paj@kt.dtu.dk
}

\begin{abstract}
This study provides a simple model for biomass char yield obtained under conditions relevant for suspension firing. Using the multivariate data analysis methods, principal component analysis (PCA) and partial least squares regression (PLS regression), an equation is presented, which predict the char yield for wood and herbaceous biomass. The model parameters are heating rate $\left(0.1-12 \cdot 10^{3} \mathrm{~K} / \mathrm{s}\right)$, average particle size $(0.13$ $0.93 \mathrm{~mm}$ ), maximum temperature $(873-1673 \mathrm{~K})$, potassium content (from $0.02 \mathrm{wt} \%$ $\mathrm{db}$ and upwards), and char yield (1-15 wt\% daf). The model is developed based on wood biomass data and subsequently expanded to include straw and other herbaceous biomass. It is validated against experimental data from the literature and in general it exhibits the same characteristics. Independent data sets of wood are predicted with an average error (RMSEP) of 0.9 wt\%point daf, and straw with an RMSEP $=0.9 \mathrm{wt} \%$ daf for the model, when a slope/intercept correction is applied, or RMSEP $=1.1 \mathrm{wt} \%$ daf otherwise. To include herbaceous biomass, the model introduces a potassium cut off level at $0.53 \mathrm{wt} \% \mathrm{db}$, because the catalytic effect of potassium on the devolatilization


process levels off above this concentration. The model consists of one equation, making implementation into CFD and devolatilization models possible without adding to the computational costs.

\section{Introduction}

The increased awareness of climate change has resulted in a demand for a more sustainable power and heat production. One possible option is suspension firing of biomass, which is often economically advantageous, because biomass particles can be utilized in existing boilers originally constructed for coal combustion. Combustion of single particles, regardless of whether it is coal or biomass, in suspension fired boilers includes devolatilization followed by volatile and char combustion. The combustion of the released volatiles happens relatively fast within the visual flame, while the char combustion is a more time consuming process. ${ }^{1,2}$ Consequently, it is important to know the fractions of volatiles and char for prediction of the burnout of the fuel. The volatile and char fractions are also often used as input parameters in combustion models. ${ }^{3-5}$ Differences between coal and biomass particles include e.g. particle size, chemical composition, and volatile fraction; ${ }^{6}$ which influence the obtainable char yield. Since so many parameters influence the process, char yield fractions are often determined experimentally for each individual fuel batch, but this is time-consuming and laborious under suspension firing conditions.

Several experimental studies ${ }^{7-12}$ have investigated how typical suspension fired conditions influence the char yield of different types of biomass. Typical condition for suspension firing include high heating rates $(>1000 \mathrm{~K} / \mathrm{s})$, high final temperatures $(>1000 \mathrm{~K})$, and small particles $(<3 \mathrm{~mm})$. For fully devolatilized wood particles char yields in the range 1-15 wt\% dry ash free basis (daf) have been observed. ${ }^{7,8}$ Experimental results obtained under suspension firing conditions have shown that particle size ${ }^{7-9}$ final temperature, ${ }^{7,8,10,11}$ heating rate ${ }^{8}$ and alkali content ${ }^{7,8,12}$ influence the obtained char yield. Higher values for both particle size 
and potassium content result in a higher char yield for suspension firing conditions. For an increase in particle size the tendency is weak, ${ }^{8}$ whereas the potassium content shows a strong correlation to char yield up to approximately $0.5 \mathrm{wt} \% \mathrm{db}$ of the biomass. ${ }^{8}$ Values above 0.5 $\mathrm{wt} \% \mathrm{db}$ seem not to change the char yield further. An increase in final temperature and/or heating rate yields an exponentially decreasing correlation with char yield. ${ }^{8}$

In this study, the influence of different experimental and material parameters on biomass char yield has been examined through multivariate data analysis. The use of multivariate data analysis to determine biomass thermal conversion properties is limited, but a few examples have been found in literature. Acquah et al. ${ }^{13}$ have made a chemometric analysis for predicting the results of thermogravimetric analysis (TGA) experiments, Kim et al. ${ }^{14}$ used principal component analysis (PCA) to study biomass properties after exposure to $\mathrm{CO}_{2}$, and wood pellet properties have been studied using PCA by both Toscano et al. ${ }^{15}$ and Mancini et al. ${ }^{16}$ To the knowledge of the authors, no papers predicting the char yield of high heating rate experiments with the help of multivariate data analysis have been published. Neves et al. ${ }^{17}$ made an empirical model for char yield obtained from devolatilization at final temperatures up to $1273 \mathrm{~K}$ and heating rates in the order $1-100 \mathrm{~K} / \mathrm{s}$. Trubetskaya et al. ${ }^{18}$ made a one dimensional kinetic model of the char yield, fitting a set of differential equations.

This paper has two main purposes. First, it presents an exploratory investigation into data from devolatilization of biomass under suspension firing conditions using the key input parameters; particle size, final temperature, heating rate, and potassium content. This investigation is conducted through a principal component analysis (PCA). Subsequently, a model using aforementioned data to predict char yield is presented. The prediction model is calculated using partial least squares regression (PLS). The model is interpreted; evaluating the importance of the input parameters in a quantifiable way. The prediction model is simple, so it can be implemented into more complicated models and CFD simulations without 
adding substantial computational time.

\section{Method}

Chemometrics is the subject of extracting information from chemical measurements with a statistical approach. Commonly used methods within chemometrics are PCA and PLS. ${ }^{19-21}$ In depth descriptions of PCA and PLS is beyond the scope of this paper, but can be found in the literature. ${ }^{19-24}$ The PCA and PLS models presented here are made in PLS Toolbox version 8.1.1, Matlab version 9.3.0 (R2017b). The data have been extracted from the relevant papers using WebPlotDigitizer version 4.1.

\subsection{Definitions of Parameters used for Model Development}

The input parameters to the models are particle size, final temperature, heating rate, and potassium content, as they affect char yield from high heating rate biomass devolatilization. ${ }^{8,17}$ In the scope of this paper particle size is defined as the average between the upper and the lower sieve sizes used for determination of biomass particle size. The sieve size average is used because it is frequently available and for simplicity. As biomass can vary in size and shape, more complicated measures exist. ${ }^{25}$ Final temperature is the final or maximum temperature of the applied reactor. Heating rate can be obtained, e.g., via a thermocouple in a wire mesh reactor. Otherwise the heating rate is estimated as described in supplementary material. The potassium content is here defined as the potassium content in wt\% dry basis $(\mathrm{db})$ of the original biomass. In papers where the potassium content is not published it is estimated as described in the supplementary material. The Char yield is defined as the percentage of ash free char from a dry ash free biomass sample. 


\subsection{Selection of Data Applicable for Model Development}

The interest of this study is the final char yield after suspension firing, hence only data for fully devolatilized particles have been used both for model development and model evaluation. The data set used for developing the model is obtained in a wire mesh reactor (WMR) and a drop tube reactor (DTR), originates from Trubetskaya et al. ${ }^{8,10}$ and will be referred to as the calibration set. Any data, which fulfills the requirements indicated below will be used for independent validation of the model, and is referred to as the validation set. The papers used for validation are given in table 2. The data have been obtained in EFRs and DTRs as noted in the table. Particles were considered to have obtained full devolatilization if a paper showed consistent results for particle yield fractions over time and/or the residence time was long compared to the particle size. ${ }^{8}$ Data which describe the char yield for fully devolatilized particles are scarce in literature, and papers, ${ }^{26-32}$ which do not provide data on fully devolatilized particles have been omitted from the study. Likewise, papers, ${ }^{33,34}$ where the experimental conditions are outside the parameter intervals for the calibration data set, are also omitted from this study. The parameter intervals are given in table 1 for woody biomasses. Furthermore, char yield data ${ }^{35,36}$ obtained from reactor types (e.g. fluid bed reactors), where particle and operating conditions are vastly different from suspension firing conditions, may not be comparable and have been disregarded.

As the amount of published data describing char yield for non-wood biomass is limited, the presented model is developed based on wood biomass only. Considerations regarding expansion of the model to include herbaceous biomass char yield is presented in section 3.5 and 3.6. The parameter spans valid for the herbaceous char yield model are identical to the ones presented in table 1, except the potassium content, which has no upper limit for the herbaceous model. 
Table 1: Parameter span for which the model for wood biomass is made. The full data set containing 37 data points from Trubetskaya et al. ${ }^{8,10}$ can be seen in the supplementary material. The herbaceous biomass model use the same parameter spans except for the potassium content, where there is no upper limit; see section 3.6. * Estimated value as described in the supplementary material.

\begin{tabular}{lrr}
\hline Parameter & min & $\max$ \\
\hline Size $[\mathrm{mm}]$ & 0.13 & 0.93 \\
Final Temperature $[\mathrm{K}]$ & 873 & 1673 \\
Heating rate $\left[10^{3} \mathrm{~K} / \mathrm{s}\right]$ & 0.10 & $12^{*}$ \\
K content $[\mathrm{wt} \% \mathrm{db}]$ & 0.02 & 0.37 \\
\hline
\end{tabular}

Table 2: Data used for model evaluation. Only data for fully devolatilized particles are taken from the cited papers. Data above the dashed line are from wood biomass experiments. Data below the dashed line are from herbaceous material. * Estimated value as described in supplementary material. $\mathrm{HR}=$ Heating rate. $\#=$ Number of data points. $\mathrm{EFR}=$ Entrained flow reactor. DTR $=$ Drop tube reactor. Potassium levels in herbaceous material is accounted for in section 3.6. Typical potassium levels in Cynara Cardunculus (used by Jiménez et al. ${ }^{37}$ ) is studied by Solano et al. ${ }^{38}$ and the potassium content is taken from the latter.

\begin{tabular}{|c|c|c|c|c|c|c|c|}
\hline & Paper & $\begin{array}{l}\text { Reactor } \\
{[\mathrm{mm}]}\end{array}$ & $\begin{array}{l}\text { Part. size } \\
{[\mathrm{K}]}\end{array}$ & $\begin{array}{l}\text { Final Temp. } \\
{\left[10^{3} \mathrm{~K} / \mathrm{s}\right]}\end{array}$ & $\begin{array}{l}\text { HR } \\
\text { [wt \%db] }\end{array}$ & K content & $\#$ \\
\hline $\mathbf{A}$ & Chen et al. ${ }^{39}$ & DTR & 0.35 & 1073 & $2.4^{*}$ & $0.05^{*}$ & 1 \\
\hline B & Dall'Ora et al. ${ }^{7}$ & EFR & 0.30 & $1273-1573$ & $4.6-11^{*}$ & $0.03-0.1$ & 4 \\
\hline $\mathrm{C}$ & Septien et al. ${ }^{9}$ & DTR & $0.36-0.82$ & $1273-1673$ & $1.2-8.1^{*}$ & $0.08-0.09$ & 6 \\
\hline D & Zhang et al. ${ }^{11}$ & DTR & 0.25 & 1273 & $12^{*}$ & $0.03^{*}$ & 1 \\
\hline$\overline{\mathbf{E}}^{-}$ & Jiménez et al. ${ }^{37}$ & $\overline{\mathrm{EFR}}$ & $0 . \overline{3} 5$ & $\overline{10} \overline{7} \overline{3}-\overline{14} \overline{4} \overline{8}$ & $10^{-}$ & $>0.53^{*}$ & 4 \\
\hline
\end{tabular}

\subsection{Preprocessing}

Preprocessing is performed to develop a robust model. The parameters have been preprocessed individually to ensure linearity between parameters and char yield, as PLS is a linear regression method. The reader is referred to figure $2-4+6$ in the paper $^{8}$ where the calibration set is originally presented for documentation of the correlations between the four independent parameters and char yield. For particle size the correlation seems linear, so no individual preprocessing method is applied here. Final temperature and heating rate show an exponentially decreasing correlation to char yield. It is, however, possible that it 
can be approximated by a linear correlation in the parameter span relevant for suspension firing. Both a logarithmic and no individual preprocessing (linear correlation) are tested as possibilities. The potassium content seems to have a linear correlation to char yield until approximate $0.5 \mathrm{wt} \% \mathrm{db},{ }^{8}$ above which the effect of the potassium levels off. As the latter is only relevant for non-woody biomass, since no woody samples had potassium levels above $0.5 \mathrm{wt} \% \mathrm{db}$, no preprocessing of the potassium content parameter has been tested. An overview of the combinations in which the preprocessings have been tested is presented in table 3. The data is collected in two matrices; $\mathbf{X}$ containing values for the independent variables, and $\mathbf{Y}$ containing the dependent char yield values.

All parameters in the presented model have additionally been scaled to account for unit variance, to ensure that parameters contribute numerically equal regardless of the unit in which they have been measured.

\subsection{Cross Validation}

The cross validation performed in this study is based on the random subset method, because the information, regarding duplicates and chronology of experiments in the papers ${ }^{8,10}$ containing the data used for the calibration set, is scarce. The random subset method is described by Dubitzky et al. ${ }^{40}$ and ensures that the entire parameter span is used for cross validation. In this paper the cross validation is made with six splits and six iterations, i.e. each subset consists of approximately $17 \%$ of the data set. The cross validation is performed at least ten times for all models described in table 3. The explained variances in $\mathbf{Y}$ and RMSECV values are averages of the performed cross validations. The calibration set contains two different types of woody biomass, pine and beech. A common cross validation approach is to remove one type of biomass to see if the remaining biomass type would give similar results. In this case, however, it could lead to dubious results, due to the differences in char yield values. In other words, as the two biomass types are primarily producing two 
different ranges of char yield values, using one type to predict the other would require an extrapolation of the model, which is undesirable.

\section{Results}

\subsection{Principal Component Analysis}

A PCA reveals systematic behavior in a data set. Ideally the data should be normally distribution, but even when this is not the case PCA can reveal some systematic behavior in a data set. In this case only the first two principal components (PCs) are deemed of interest, so only these are shown in figure 1 . The loading plots for figure 1 can be seen in supplementary material. In the direction of the first PC there is a separation of the data points into biomass type. Within each biomass type there is also a correlation to char yield in the direction of the first PC. In the direction of the second PC the scattering due to differences in char yield is more pronounced. Since the data show systematic behavior with respect to char yield in the PCA, a PLS model is developed.

\subsection{Partial Least Squares Regression Model}

The PLS model is developed to be able to predict the char yield of woody biomasses and thereby also the volatile yields. The preprocessing methods described in section 2.3 have been tested in different combinations reported in table 3. 
(b) Preprocessed variables corresponding to model 10 presented in table 3 . Some of the pine samples are located identically, which means not all are visible in this plot.

Figure 1: PCA plot for the 37 biomass data points from Trubetskaya et al. ${ }^{8,10}$ given in supplementary material colored by char yield [wt\%daf]. Explained variances in PC1 and PC2 are given in the parentheses on the axes. Loading plots can be seen in supplementary material.

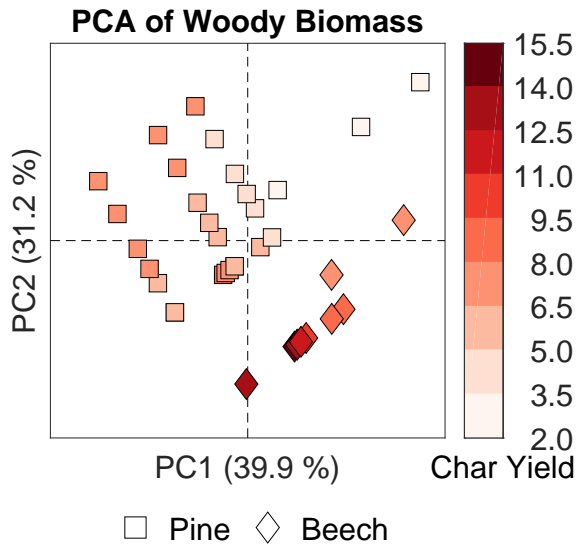

(a) Original variables.

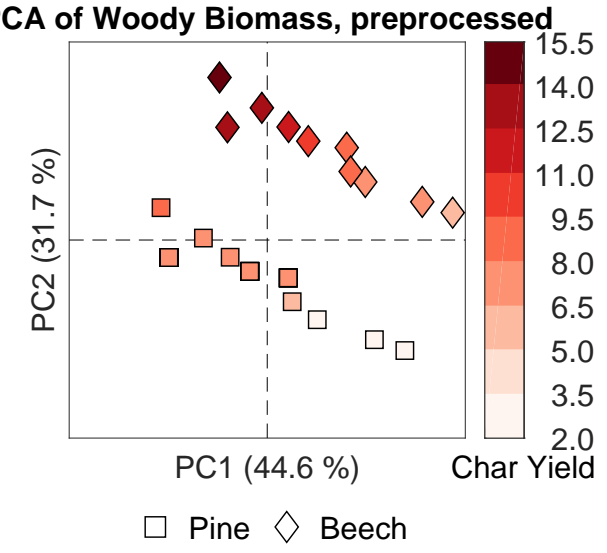


Table 3: Overview of tested PLS models for wood biomass. All models are made with one PLS component. ExpVarY and RMSECV are average values of at least ten cross validation runs. ExpVarY $=$ Explained variance in $\mathbf{Y}, \mathrm{FT}=$ final temperature, $\mathrm{HR}=$ heating rate, $\mathrm{KC}=$ potassium content, $\mathrm{CY}=$ char yield. $\mathrm{x}=$ parameter is included. $-=$ parameter not included directly as input parameter.

\begin{tabular}{|c|c|c|c|c|c|c|c|}
\hline $\begin{array}{l}\text { Model } \\
\#\end{array}$ & Size & FT & HR & $\mathbf{K C}$ & $\mathrm{CY}$ & $\begin{array}{l}\operatorname{Exp} \operatorname{Var} Y \\
{[\%]}\end{array}$ & $\begin{array}{l}\text { RMSECV } \\
\text { [wt\%points daf] }\end{array}$ \\
\hline 1 & $\mathrm{x}$ & $\mathrm{x}$ & $\mathrm{x}$ & $\mathrm{x}$ & $\mathrm{x}$ & 72.9 & 1.6 \\
\hline 2 & $\mathrm{x}$ & $\mathrm{x}$ & $\log (\mathrm{x})$ & $\mathrm{x}$ & $\mathrm{x}$ & 81.8 & 1.3 \\
\hline 3 & $\mathrm{x}$ & $\log (\mathrm{x})$ & $\log (\mathrm{x})$ & $\mathrm{x}$ & $\mathrm{x}$ & 81.7 & 1.4 \\
\hline 4 & $\mathrm{x}$ & $\mathrm{x}$ & $\log (\mathrm{x})$ & $\mathrm{x}$ & $\log (\mathrm{x})$ & 81.5 & 1.1 \\
\hline 5 & $\mathrm{x}$ & $\log (\mathrm{x})$ & $\log (\mathrm{x})$ & $\mathrm{x}$ & $\log (\mathrm{x})$ & 81.3 & 1.1 \\
\hline 6 & - & $\mathrm{x}$ & $\mathrm{x}$ & $\mathrm{x}$ & $\mathrm{x}$ & 77.6 & 1.5 \\
\hline 7 & - & $\mathrm{x}$ & $\log (\mathrm{x})$ & $\mathrm{x}$ & $\mathrm{x}$ & 88.6 & 1.1 \\
\hline 8 & - & $\mathrm{x}$ & $\mathrm{x}$ & $\mathrm{x}$ & $\log (\mathrm{x})$ & 80.5 & 1.4 \\
\hline 9 & - & $\mathrm{x}$ & $\log (\mathrm{x})$ & $\mathrm{x}$ & $\log (\mathrm{x})$ & 86.5 & 1.0 \\
\hline 10 & - & $\log (\mathrm{x})$ & $\log (\mathrm{x})$ & $\mathrm{x}$ & $\log (\mathrm{x})$ & 86.5 & 1.0 \\
\hline 11 & - & $\log (\mathrm{x})$ & $\log (\mathrm{x})$ & $\mathrm{x}$ & $\mathrm{x}$ & 88.8 & 1.1 \\
\hline
\end{tabular}

Based on the RMSECV and explained variance in $\mathbf{Y}$, the most well-performing models are number $7,9,10$, and 11 . As previously noted a logarithmic correlation is likely between the final temperature and the char yield, hence model 10 and 11 are preferred over model 7 and 9. All graphs presented in the paper have been inspected for both model 10 and 11, but as they are qualitatively similar; only one set will be presented. Since the RMSECV (and RMSEP given in section 3.4) are lower for model 10 it will be preferred. As stated in table 3 the size parameter is not included in model 10, and in general when the size parameter is included the regression models seem to predict the char yield less accurately than when it is omitted. This will be discussed in the subsequent section 4. One PLS component is used for prediction in all the PLS models reported here. Various plots were inspected for outlier detection, but none have been found. An example of hotelling $\mathrm{T}^{2}$ vs $\mathrm{Q}$ residuals is presented in the supplementary material. 


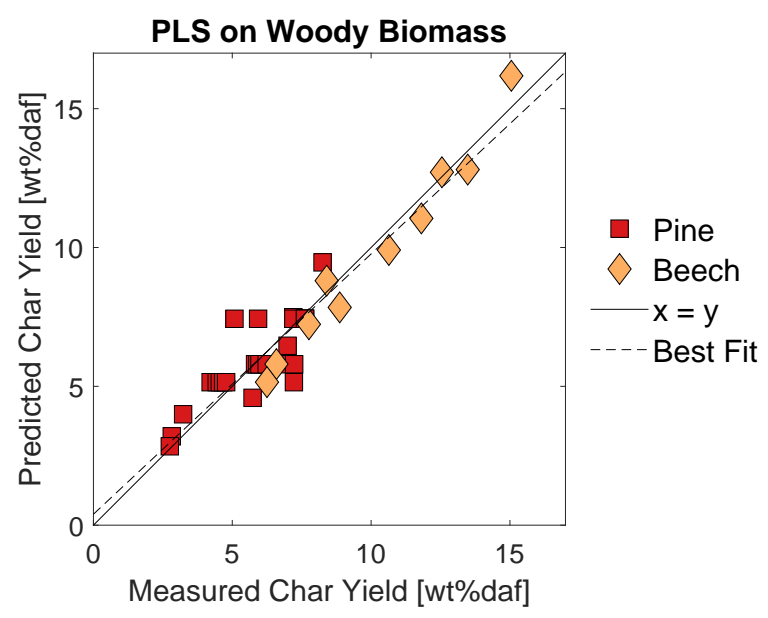

Figure 2: PLS plot of model 10 for the wood biomass calibration set.

In figure 2 the cross validated predicted char yields have been plotted as a function of the measured char yield for model 10. The figure shows good agreement between the two, and the model has RMSECV $=1.0 \mathrm{wt} \%$ point and $r^{2}=0.87$. The model is condensed to a regression vector, which is given both for the preprocessed data and for the raw data in table 4 .

Table 4: Regression vectors for model 10.

\begin{tabular}{lll}
\hline Parameter & $\begin{array}{l}\text { Reg. vec. } \\
\text { (Preprocessed) }\end{array}$ & $\begin{array}{l}\text { Reg. vec. } \\
\text { (Raw data) }\end{array}$ \\
\hline Intercept & 0 & 3.4370 \\
$\log (\mathrm{FT})$ & -0.4521 & -0.6598 \\
$\log (\mathrm{HR})$ & -0.6850 & -0.2130 \\
K content & 0.5713 & 0.6852 \\
\hline
\end{tabular}

The char yield can be predicted for new data, by converting the regression vector values back to the values, they would have without the preprocessing. Thus the char yield from wood devolatilization can be predicted for new data from equation (1).

$$
C Y_{\text {wood }}=10^{3.4370+0.6852 \cdot K C-0.6598 \cdot \log (F T)-0.2130 \cdot \log (H R)}
$$

Here $C Y_{\text {wood }}$ is the char yield in wt\%daf, $K C$ is the potassium content in wt\%db, $F T$ is the final temperature in $\mathrm{K}$, and $H R$ is the heating rate in $\mathrm{K} / \mathrm{s}$. 


\subsection{General Tendencies}

The general tendencies predicted by the model can be seen in figure $3 \mathrm{a}$ through $3 \mathrm{c}$. In figure $3 \mathrm{a}$ it can be seen that the char yield decreases for increasing final temperature. In figure $3 \mathrm{~b}$ it can be seen that the char yield decreases rapidly with increasing heating rate in the lower end of the heating rate range and that the changes are leveling out for higher values of the heating rate. Both figure $3 \mathrm{a}$ and $3 \mathrm{~b}$ show an exponential correlation between heating rate, final temperature, and char yield. Figure $3 \mathrm{c}$ shows that the char yield increases as a function of increasing potassium concentrations in the biomass. All these findings are in good agreement with the experimental observations made by Dall'Ora et al., ${ }^{7}$ Trubetskaya et al., ${ }^{8}$ and Septien et al. ${ }^{9}$ 
3 4 5 6 7 8 9

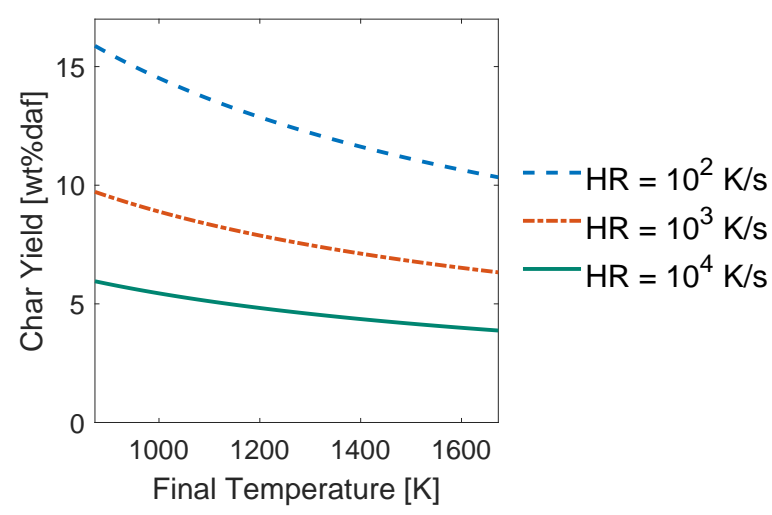

(a) $\mathrm{K}$ content $=0.19 \mathrm{wt} \% \mathrm{db}$.

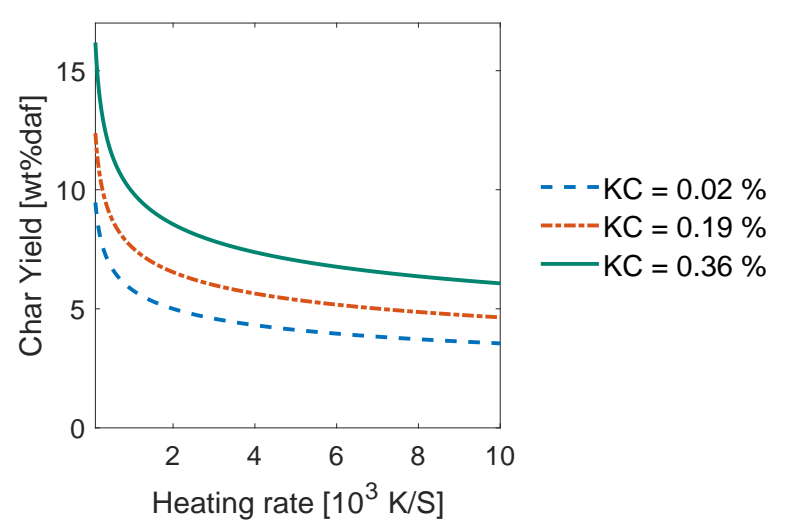

(b) Final Temperature $=1273 \mathrm{~K}$.

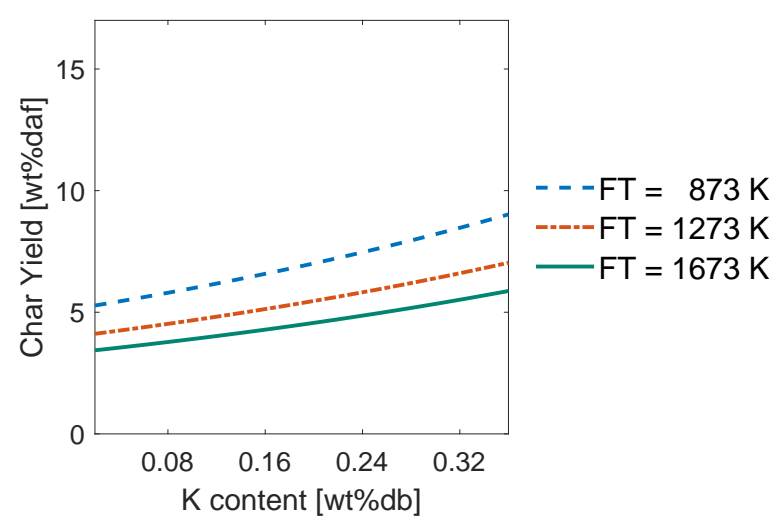

(c) Heating rate $=5000 \mathrm{~K} / \mathrm{s}$.

Figure 3: Model predictions for different parameters. $\mathrm{HR}=$ Heating rate, $\mathrm{KC}=$ potassium content in $[\mathrm{wt} \% \mathrm{db}], \mathrm{FT}=$ Final temperature. 


\subsection{Model Validation with External Data}

The model has been validated with data from external experimental studies given in table 2 . The predicted and measured char yield values for the external data is depicted in figure 4 .

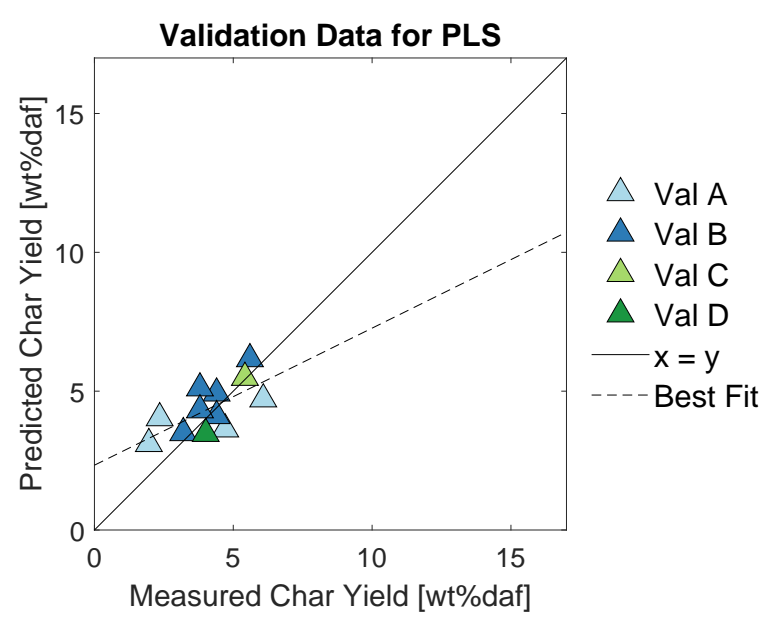

Figure 4: PLS plot for model 10 for the validation data given in supplementary material. Best fit line is for the validation data. Val A from Dall'Ora et al., ${ }^{7}$ Val B from Septien et al., ${ }^{9}$ val $\mathrm{C}$ from Chen et al., ${ }^{39}$ and Val D from Zhang et al. ${ }^{11}$ The validation data are only in the lower end of the char yield range. The axes values are the same as in figure 2 for comparability.

The figure shows predicted vs. measured char yield for the validation data. There are limited data available for external validation, but in general the data are predicted well. More data, especially in the upper char yield range, would be preferable in order to evaluate this part of the model as well. The root mean squared error of prediction (RMSEP) is 0.9 wt\%points for the external data. I.e., the average error for predicted biomass char yield for the completely independent data sets is $\pm 0.9 \mathrm{wt} \%$ points which is low and similar to the RMSECV value of $1.0 \mathrm{wt} \%$ points, indicating that the model is robust.

\subsection{Predicting Char Yield of Straw}

Straw is also a commonly used biomass fuel in suspension fired boilers. Trubetskaya et al. ${ }^{8,10}$ have conducted experiments with wheat straw, but no additional wheat straw data obtained under suspension firing conditions applicable as validation data have been found. 


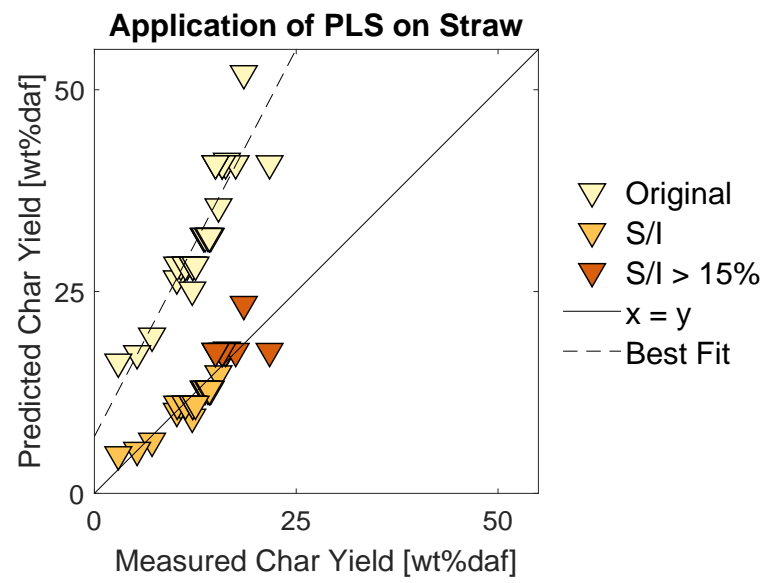

Figure 5: Predicted vs. measured char yield for model 10 in [wt\%daf] for straw data by Trubetskaya et al. ${ }^{8,10}$ both for the original and the slope/intercept corrected model. The measured char yield data above $15 \mathrm{wt} \%$ daf are colored a darker orange to indicate which predicted values are found by extrapolation of the model. $\mathrm{S} / \mathrm{I}=$ slope/intercept corrected model. The dashed best fit line is for the original model. The slope intercept corrected model has been corrected to have the best fit as the $\mathrm{y}=\mathrm{x}$ line. Straw data is given in the supplementary material.

The slope/intercept correction is further supported by the results in figure $6 \mathrm{a}$ and $6 \mathrm{~b}$, 
which show PCA plots for the original calibration set together with validation data and straw data. Since the validation data for wood are occupying the same space in the PCA vector space as the calibration set, it is plausible that the prediction model is applicable also for the validation set, which is in good agreement with the results observed in section 3.4. The straw data are located away from the calibration set in the PCA plot, so applying the char yield model for wood directly as presented in equation (1) is not likely to yield useful results. The differences in locations in the PCA plots are primarily attributable to the potassium content being higher for straw. However, it is worth noticing that the tendency with respect to char yield in the PCA vector space is the same for straw and woody data, so a slope/intercept corrected model is appropriate. Since some of the char yields for the straw exceed the maximum char yield in the calibration set, these data points have been excluded before making the slope/intercept correction. They are removed because having to extrapolate a PLS model is generally not advisable. As can be seen in figure 5 the removed straw data are approximately located on a straight line with the same slope as the remaining straw data, so the changes obtained by removing them are minor. A comparison of the model statistics with and without char yield data above $15 \mathrm{wt} \%$ daf and the original straw data can be seen in table 5. The expression for straw char yield can be seen in equation (2). The equation has not been validated against an external validation set and should thus be used more cautiously than the model for wood biomass, especially if the potassium content is vastly different in the sample one wants to predict the char yield of.

$$
C Y_{\text {Straw }}=\frac{10^{(3.4370+0.6852 \cdot K C-0.6598 \cdot \log (F T)-0.2130 \cdot \log (H R))}-10.6603}{1.4963}
$$

Here $C Y_{\text {straw }}$ is the char yield in wt\%daf, $K C$ is the potassium content in wt\%db, $F T$ is the final temperature in $\mathrm{K}$, and $H R$ is the heating rate in $\mathrm{K} / \mathrm{s}$. 


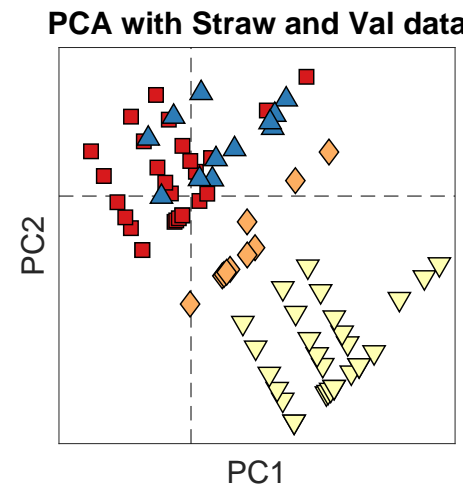

- Pine $\diamond$ Beech $\Delta$ Val $\nabla$ Straw

(a) Colored by biomass type.

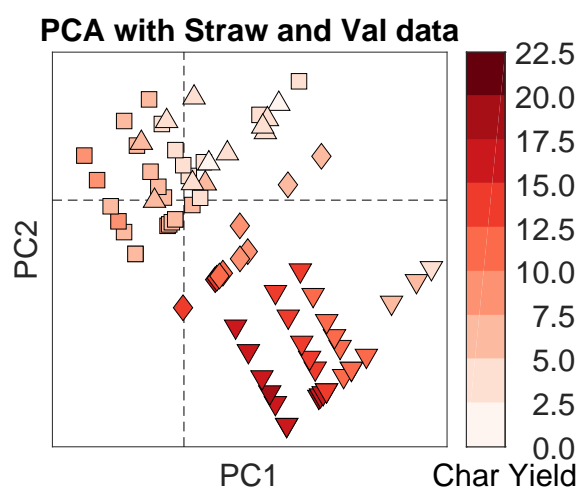

Pine

$\diamond$ Beech $\triangle$ Val $\nabla$ Straw

(b) Colored by char yield. NB. Colorbar is in a different scale than the one presented previously.

Figure 6: The validation data and straw data incorporated into the PCA first introduced in figure $1 \mathrm{a}$. 
Table 5: Model statistics for the PLS model for the cross validated calibration set for woody biomass, the validation data for woody biomass, and the straw data. The original straw model (Model 10) has been reported as well as slope/intercept corrected data with and without char yield data above 15 wt\%daf. * RMSECV. ** RMSEP.

\begin{tabular}{lll}
\hline Included Data & $\begin{array}{l}\text { RMSE } \\
{[\text { wt\%points daf }]}\end{array}$ & $\mathbf{r}^{2}$ \\
\hline Woody cross validated calibration Data, Model 10 & $1.0^{*}$ & 0.87 \\
Woody validation Data, Model 10 & $0.9^{* *}$ & 0.45 \\
Straw, Model 10 & $19.8^{* *}$ & 0.82 \\
Straw, Model 10 (S/I) & $1.8^{* *}$ & 0.82 \\
Straw, Model 10 (S/I), yield $<$ 15 wt\% daf & $0.9^{* *}$ & 0.93 \\
\hline
\end{tabular}

\subsection{Predicting Char Yield of Herbaceous Material}

Straw is not the only herbaceous material used for suspension firing and a more broadly applicable char yield model would be advantageous. A possible way of modifying the model for wood presented in equation (1) in order to include additional biomass species is to determine the potassium concentration at which the catalytic effect of this compound levels off. An advantage of this approach is a more versatile model, but it comes at the cost of lower model accuracy. The cut off level for the effect of potassium is here determined from the wheat straw experimental data by Trubetskaya et al., ${ }^{8,10}$ and the cut off level is then tested for other herbaceous material experimental data by Trubetskaya et al. ${ }^{8,10}$ and independent data by Jiménez et al. ${ }^{37}$

As previously mentioned, the linear correlation observed in the experimental data between char yield and potassium content levels off around $0.5 \mathrm{wt} \% \mathrm{db}$, so the $1.1 \mathrm{wt} \% \mathrm{db}$ reported for the straw in the experiments used for model generation will likely cause an overshoot in the prediction of the char yield, if the wood model were used. However, if the wood model is used with a correction in potassium content, some of the differences between wood and herbaceous biomass can be highlighted. To determine the concentration, where the effect of potassium levels off, the RMSEP for the straw is used as an optimization parameter; 
the lower the RMSEP, the better. For the given straw data the potassium content, which yields the lowest squared error (RMSEP) between measured and predicted straw char yield, is $0.53 \mathrm{wt} \% \mathrm{db}$. So for biomass with a potassium content above $0.53 \mathrm{wt} \% \mathrm{db}$ the input to the model in equation (1) should be fixed at $0.53 \mathrm{wt} \% \mathrm{db}$. Figure 7 depicts the predicted vs. measured straw char yield, if one uses the wood biomass model with the real straw potassium content and with a potassium content of maximum $0.53 \mathrm{wt} \% \mathrm{db}$. This indicates that the major differences in biomass char yield for wood and straw is due to the catalytic effects of potassium in the devolatilization process. This is further strengthened when the cut off value of $0.53 \mathrm{wt} \% \mathrm{db}$ is used for other herbaceous biomass, as shown in figure 8. Using the same cut off value of $0.53 \mathrm{wt} \% \mathrm{db}$ on different herbaceous biomass types shows that the change in potassium content accounts for the majority of the difference in char yield between wood and herbaceous material in general, but the potassium content cut off value of $0.53 \mathrm{wt} \% \mathrm{db}$ is not equally good for all biomass types. RMSEP values and $r^{2}$ values for the herbaceous biomass can be seen in table 6 .

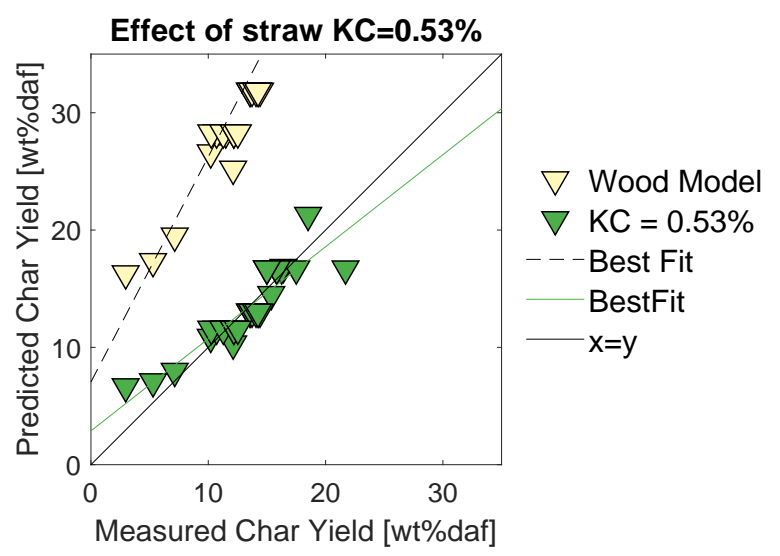

Figure 7: Predicted vs. measured char yield for model 10 in [wt\%daf] for the original straw data by Trubetskaya et al. ${ }^{8,10}$ and for the wood model with a cut off value of $\mathrm{KC}=0.53$ $\mathrm{wt} \% \mathrm{db} . \mathrm{KC}=$ potassium content. 


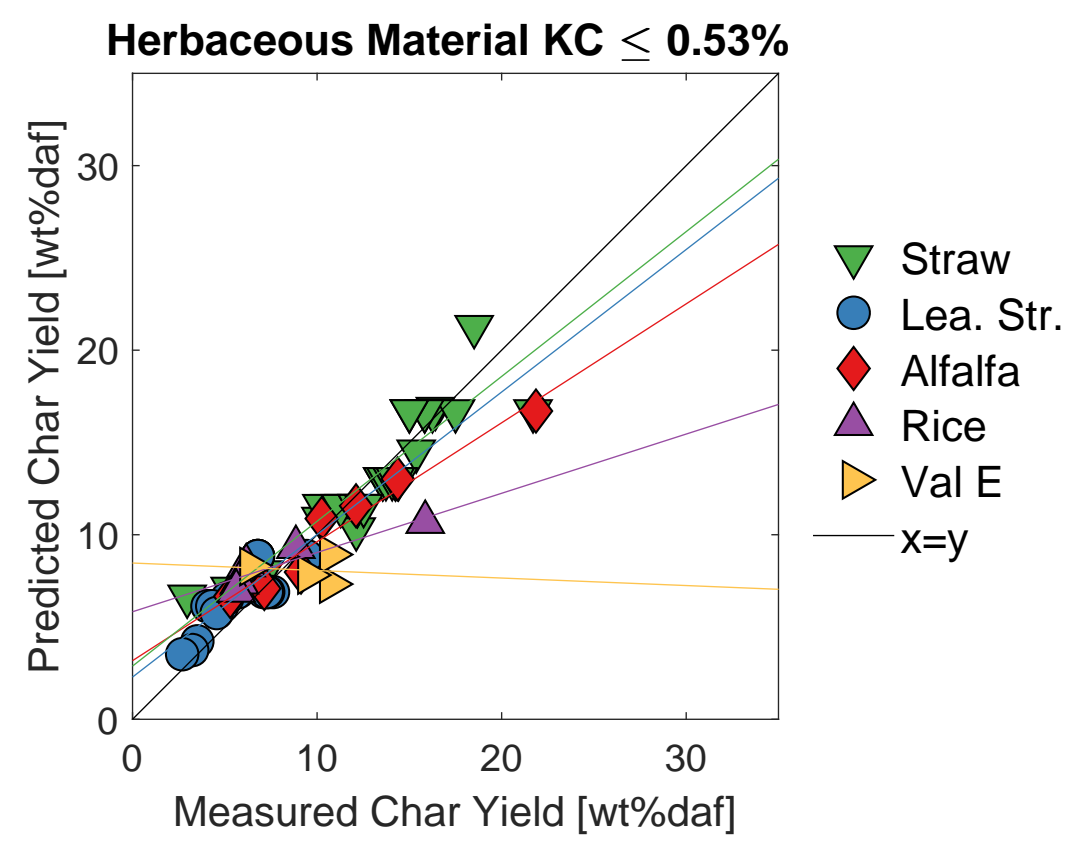

Figure 8: Predicted vs. measured char yield for model 10 in [wt\%daf] for leached wheat straw, rice husk, alfalfa, and wheat straw. The two latter have a cut off value of $\mathrm{KC}=0.53$ $\mathrm{wt} \% \mathrm{db}$. The leached wheat straw has $\mathrm{KC}=0.13 \mathrm{wt} \% \mathrm{db}$. Rice husk $\mathrm{KC}=0.25 \mathrm{wt} \% \mathrm{db}$. Val $\mathrm{E}=$ validation data from Jiménez et al. ${ }^{37}$ from Cynara Cardunculus thistle with a cut off value of $\mathrm{KC}=0.53 \mathrm{wt} \% \mathrm{db} . \mathrm{KC}=$ potassium content. Best fitted lines for all biomass types can be seen in their respective colors.

Table 6: Model statistics for herbaceous biomass with a cut off value for potassium of $0.53 \mathrm{wt} \% \mathrm{db}$ in model 10 . The cut off value for potassium has been determined by determining the minimal possible RMSEP for the straw data, all data points included. Validation data are below dashed line.

\begin{tabular}{|c|c|c|}
\hline Biomass Type & $\begin{array}{l}\text { RMSEP } \\
\text { [wt\%points daf] }\end{array}$ & $\mathbf{r}^{2}$ \\
\hline Wheat Straw & 1.6 & 0.82 \\
\hline Wheat Straw, yield $<15 \mathrm{wt} \%$ daf & 1.1 & 0.93 \\
\hline Leached Wheat Straw & 1.4 & 0.70 \\
\hline Alfalfa & 2.2 & 0.95 \\
\hline Rice husk & 2.7 & 0.86 \\
\hline T̄histle $\overline{(V \bar{l}} \overline{\mathrm{E}} \overline{\mathrm{C}}$ & 2.3 & $0 . \overline{0} 1$ \\
\hline
\end{tabular}




\section{Discussion}

The model is generally good at predicting char yield from woody biomass from both the calibration data set and from externally sourced data with RMSECV $=1.0 \mathrm{wt} \%$ point and RMSEP $=0.9$ wt\%point, respectively. Model validity is further supported by the PCA, which shows that the char yield is correlated to one or more parameters in the data set. Expansion of the model to include wheat straw, by a slope/intercept correction, also yields good modeled results; RMSEP $=0.9 \mathrm{wt} \%$ point for straw with a char yield below 15 wt\%daf. The model is further expanded to include different herbaceous biomass of higher potassium contents. For the versatile model, the RMSEP $=1.1$ wt\%daf for straw with a char yield below 15 wt\%daf.

An advantage of developing a model using chemometrics is the prevention of bias in the selection of which parameters should have the most influence in the model, namely false assumptions about how the parameters influence the char yield and which physical phenomena are more important. Parameters are only excluded from the developed model if they do not enhance the prediction accuracy of the desired dependent parameter, specifically the char yield.

In this study, the particle size is excluded as input parameter to the model in the development process, because inclusion decreases the model accuracy. This can be observed by comparing the model statistics for models 1-5 with the ones for models 6-11 in table 3, where the RMSECV and the explained variance in $\mathbf{Y}$ both increase when the size is excluded. It is possible that the reduction to a simple mean sieve size is too crude an estimate for a biomass

particle distribution, as biomass particle sizes are generally difficult to determine. ${ }^{25}$ Even when the size parameter is omitted it is still implicit in the model as the size affects the wood particle heating rate. 
The heating rate can be difficult to determine accurately. In a WMR, which was used to generate most of the calibration set data, ${ }^{8}$ the heating rate can be controlled, but in other reactor types it must be estimated, as seen in the supplementary material. In the present work, a simple model is utilized to estimate particle heating rates, based on the assumption that the calculated heating rate for an isothermal particle is a reasonable approximation of the heating rate in the real particle. The larger the particle, the worse the assumption with respect to isothermicity. The assumption is justifiable, because the model yields consistent results both through the cross and external validation.

The potassium cut off value of $0.53 \mathrm{wt} \% \mathrm{db}$ for biomass is useful in expanding the model to include more biomass types. It is, however, also an additional parameter, which has been fitted, and which requires validation. The cut off value results in RMSEP $=2.2 \mathrm{wt} \%$ daf for alfalfa and RMSEP $=2.3 \mathrm{wt} \%$ daf for thistle, which is comparable to the RMSEP values for the herbaceous biomass with lower potassium levels. The accuracy of the model should be considered taking into account that the char yield is usually otherwise determined by proximate analysis, which overestimates the char yield for suspension firing conditions more than is the case for the model presented here.

For all models presented in this paper there is a tendency that the char yield is slightly overpredicted for low char yields and underpredicted for high char yields as indicated by the best fit lines in figures 2, 4, 7, and 8. This indicates that the model does not account for extreme values very well and that the PLS models do not account for all variations in the data sets. One possibility of enhancing prediction would be to develop PLS models with a higher number of input parameters, which would also allow for a higher number of PLS components in the model development phase. A disadvantage in using more input parameters is that usefulness of the model diminishes if complicated measurements are necessary to determine the char yield. For the purpose of presenting a simple model for biomass char 
It is possible to increase the quality of the model by conducting additional devolatilization experiments in EFRs and WMRs. This should be done primarily to explore the design space more systematically, but also to increase the amount of experimental data. In the design space covered by the experiments for the calibration set, the input parameters are correlated to the degree seen in the correlation coefficient chart in figure 9 . The chart gives the correlation (negative or positive) between the input parameter values chosen in the experiments. The higher the absolute value in the coefficient chart, the more the two parameters are correlated in the conducted experiments. It is advantageous not to have a high correlation between parameters in order to be able to determine the effects of the individual parameters. Despite being generally good, the chart still suggests that variations in the particle size have not been tested equally for the two wood types, which would have been optimal. The correlation between heating rate and final temperature might be more difficult to separate as they are physically linked, but more WMR experiments could decouple these two parameters. 


\begin{tabular}{|c|c|c|c|c|c|c|}
\hline & $\mathrm{HR}$ & $\mathrm{FT}$ & $\mathrm{KC}$ & Size & $\log (\mathrm{HR})$ & $\log (\mathrm{FT})$ \\
\hline $\mathrm{HR}$ & & 0.46 & 0.14 & -0.04 & 0.85 & 0.41 \\
\hline $\mathrm{FT}$ & 0.46 & & 0.14 & -0.03 & 0.32 & 0.995 \\
\hline $\mathrm{KC}$ & 0.14 & 0.14 & & -0.38 & 0.06 & 0.14 \\
\hline $\mathrm{Size}$ & -0.04 & -0.03 & -0.38 & & 0.10 & -0.05 \\
\hline $\log (\mathrm{HR})$ & 0.85 & 0.32 & 0.06 & 0.10 & & 0.28 \\
\hline $\log (\mathrm{FT})$ & 0.41 & 0.995 & 0.14 & -0.05 & 0.28 & \\
\hline
\end{tabular}

Figure 9: Correlation coefficient chart for the parameters used to obtain the calibration set of wood biomass data.

\section{Conclusion}

Often a proximate analysis is used to determine the char yield for a biomass sample, however, for suspension firing combustion conditions with high heating rates and high final temperatures the char yields are lower. The models presented in this paper can be used to more accurate estimations of char yield under suspension firing conditions.

Through PCA and PLS experimental char yield data from woody biomass particles have been used to develop a simple model for predicting the char yield of woody biomass with an RMSECV $=1.0 \mathrm{wt} \%$ daf. The input parameters for the model are final temperature, heating rate, and potassium content. Validation of the model has been carried out using experimental data from four different studies, which gave an RMSEP $=0.9$ wt\%daf. The model has been expanded to include wheat straw by applying a slope/intercept correction, which yielded an RMSEP $=0.9$ wt\%daf. At a slight cost in model accuracy the model is 
further expanded to include all herbaceous biomass. This gives RMSEP $=1.1 \mathrm{wt} \%$ daf for straw, and slightly higher RMSEP values for other herbaceous biomass. The expansion is conducted by determining the potassium content, where the catalytic effects of potassium on the devolatilization process levels off. The value is determined to be $0.53 \mathrm{wt} \% \mathrm{db}$. Thus the char yield of biomass can be determined from equation (1) repeated below.

$$
C Y_{\text {biomass }}=10^{3.4370+0.6852 \cdot K C-0.6598 \cdot \log (F T)-0.2130 \cdot \log (H R)}
$$

Here $C Y_{\text {biomass }}$ is the char yield in wt\%daf, $F T$ is the final temperature in $\mathrm{K}, H R$ is the heating rate in $\mathrm{K} / \mathrm{s}, K C$ is the potassium content in wt\%db, if $K C>0.53 \mathrm{wt} \% \mathrm{db}$ then $K C=0.53$ in the above equation. The model is relevant for suspension firing conditions.

\section{Acknowledgement}

The authors gratefully acknowledge the financial and advisory support received from Ørsted A/S, Burmeister and Wain Scandinavian Contractors A/S, and Rambøll A/S. We also thank the Nordic Five Tech (N5T) alliance for financial support.

\section{Supporting Information Available}

The following files are available free of charge.

- Supplementary Material: Raw data for chemometric analysis, supplementery plots from the analysis and a model for estimating missing parameters in char yield data.

\section{Nomenclature}

\section{Abbreviations}


CFD Computational Fluid Dynamics

CY Char Yield

daf dry ash free base

db dry base

DTF Drop Tube Funrnace

FT Final Temperature

HR Heating Rate

$\mathrm{KC}$ Potassium content

LV Latent Variables

PC Principal Component

PCA Principal Component Analysis

PLS Partial Least Squares regression

RMSE Root Mean Squared Error

TGA Thermogravimetric Analysis

WMR Wire Mesh Reactor

wt weight

\section{Greek Characters}

$\epsilon \quad$ emissivity coefficient

$$
\begin{array}{r}
{[-]} \\
{[\mathrm{Pa} \cdot \mathrm{s}]} \\
{\left[\mathrm{kg} / \mathrm{m}^{3}\right]} \\
{\left[\mathrm{J} /\left(\mathrm{s} \cdot \mathrm{m}^{2} \cdot \mathrm{K}^{4}\right]\right.}
\end{array}
$$

$\mu \quad$ dynamic viscosity

$\rho \quad$ density

$\sigma \quad$ Stefan-Boltzmann constant

\section{Roman Characters}

$C_{p} \quad$ specific heat capacity

$[\mathrm{J} /(\mathrm{kg} \cdot \mathrm{K})]$

$D \quad$ diameter

$g \quad$ gravity acceleration constant

$\left[\mathrm{m}^{2} / \mathrm{s}\right]$

$h \quad$ convective heat transfer coefficient

$\left[\mathrm{J} /\left(\mathrm{s} \cdot \mathrm{m}^{2} \cdot \mathrm{K}\right]\right.$ 
1

10

$k \quad$ thermal conductivity

$n \quad$ number of datapoints

$N u \quad$ Nusselt Number

Pr Prandtl Number

Re Reynolds Number

$T \quad$ Temperature

$v \quad$ velocity

y measured char yield value for experiment $i$

$\hat{y} \quad$ predicted char yield value for experiment $i$

X Matrix of independent parameters

Y Matrix of dependent parameters

\section{Sub- and Superscripts}

$p \quad$ particle

CV Cross Validation

end final or maximum value of e.g. the temperature

g gas

i index number

ini initial value

P Prediction

\section{References}

(1) Lu, Z.; Jian, J.; Jensen, P. A.; Wu, H.; Glarborg, P. Influence of Torrefaction on Single Particle Combustion of Wood. Energy Fuels 2016, 30, 5772-5778.

(2) Lu, Z.; Jian, J.; Jensen, P. A.; Wu, H.; Glarborg, P. Impact of KCl impregnation on single particle combustion of wood and torrefied wood. Fuel 2017, 206, 684-689. 
(3) Ström, H.; Thunman, H. CFD simulations of biofuel bed conversion: A submodel for the drying and devolatilization of thermally thick wood particles. Combust. Flame 2013, $160,417-431$.

(4) Johansen, J. M.; Jensen, P. A.; Glarborg, P.; Mancini, M.; Weber, R.; Mitchell, R. E. Extension of apparent devolatilization kinetics from thermally thin to thermally thick particles in zero dimensions for woody biomass. Energy 2016, 95, 279 - 290.

(5) ANSYS Fluent 17.2 Theory Guide. https://www. sharcnet.ca/Software/Ansys/17. 2/en-us/help/flu_th/flu_th_sec_disp_law4.html, 2016; Accessed: 2018-02-21.

(6) Priyanto, D. E.; Ueno, S.; Hashida, K.; Kasai, H. Energy-efficient milling method for woody biomass. Adv. Powder Technol. 2017, 28, 1660 - 1667.

(7) Dall'Ora, M.; Jensen, P. A.; Jensen, A. D. Suspension Combustion of Wood: Influence of Pyrolysis Conditions on Char Yield, Morphology, and Reactivity. Energy Fuels 2008, 22, 2955-2962.

(8) Trubetskaya, A.; Jensen, P. A.; Jensen, A. D.; Steibel, M.; Spliethoff, H.; Glarborg, P. Influence of fast pyrolysis conditions on yield and structural transformation of biomass chars. Fuel Process. Technol. 2015, 140, 205-214.

(9) Septien, S.; Valin, S.; Dupont, C.; Peyrot, M.; Salvador, S. Effect of particle size and temperature on woody biomass fast pyrolysis at high temperature $\left(1000-1400{ }^{\circ} \mathrm{C}\right)$. Fuel 2012, 97, 202-210.

(10) Trubetskaya, A.; Jensen, P. A.; Jensen, A. D.; Llamas, A. D. G.; Umeki, K.; Glarborg, P. Effect of fast pyrolysis conditions on biomass solid residues at high temperatures. Fuel Process. Technol. 2016, 143, 118-129.

(11) Zhang, Y.; Kajitani, S.; Ashizawa, M.; Miura, K. Peculiarities of Rapid Pyrolysis of 
Biomass Covering Medium- and High-Temperature Ranges. Energy Fuels 2006, 20, $2705-2712$.

(12) NikAzar, M.; Hajaligol, M. R.; Sohrabi, M.; Dabir, B. Mineral matter effects in rapid pyrolysis of beech wood. Fuel Process. Technol. 1997, 51, $7-17$.

(13) Acquah, G. E.; Via, B. K.; Fasina, O. O.; Adhikari, S.; Billor, N.; Eckhardt, L. G. Chemometric modeling of thermogravimetric data for the compositional analysis of forest biomass. PLoS ONE 2017, 12, 1-15.

(14) Kim, K.; Labbé, N.; Warren, J. M.; Elder, T.; Rials, T. G. Chemical and anatomical changes in Liquidambar styraciflua L. xylem after long term exposure to elevated $\mathrm{CO}_{2}$. Environ. Pollut. 2015, 198, 179 - 185.

(15) Toscano, G.; Rinnan, A.; Pizzi, A.; Mancini, M. The Use of Near-Infrared (NIR) Spectroscopy and Principal Component Analysis (PCA) to Discriminate Bark and Wood of the Most Common Species of the Pellet Sector. Energy Fuels 2017, 31, 2814-2821.

(16) Mancini, M.; Rinnan, A.; Pizzi, A.; Mengarelli, C.; Rossini, G.; Duca, D.; Toscano, G. Near infrared spectroscopy for the discrimination between different residues of the wood processing industry in the pellet sector. Fuel 2018, 217, 650-655.

(17) Neves, D.; Thunman, H.; Matos, A.; Tarelho, L.; Gómez-Barea, A. Characterization and prediction of biomass pyrolysis products. Prog. Energy Combust. Sci. 2011, 37, $611-630$.

(18) Trubetskaya, A.; Surup, G.; Shapiro, A.; Bates, R. B. Modeling the influence of potassium content and heating rate on biomass pyrolysis. App. Energy 2017, 194, 199-211.

(19) Wold, S.; Esbensen, K.; Geladi, P. Principal Component Analysis. Chemom. Intell. Lab. syst. 1987, 2, 37-52.

(20) Jackson, J. E. A user's guide to principal components; John Wiley \& Sons, Inc., 1991. 
(21) Eriksson, L.; Johansson, E.; Kettaneh-Wold, N.; Wold, S. Multi-and Megavariate Data Analysis. Principles and Applications, page 71; Umetrics Academy, 2003; Vol. 1.

(22) Kjeldahl, K.; Bro, R. Some common misunderstandings in chemometrics. J. Chemom. 2010, 24, 558-564.

(23) Bro, R.; Smilde, A. K. Principal component analysis. Anal. Methods 2014, 6, 28122831.

(24) Zachariassen, C. B. Process Analytical Chemistry and Technology in Pectin Production. Ph.D. thesis, Department of Food Science, University of Copenhagen, 2007.

(25) Trubetskaya, A. Fast pyrolysis of biomass at high temperatures. Ph.D. thesis, Department og Chemical amd Biochemical Engineering, DTU, 2016.

(26) Dupont, C.; Commandré, J.-M.; Gauthier, P.; Boissonnet, G.; Salvador, S.; Schweich, D. Biomass pyrolysis experiments in an analytical entrained flow reactor between $1073 \mathrm{~K}$ and 1273 K. Fuel 2008, 87, 1155-1164.

(27) Lewis, A. D.; Fletcher, T. H. Prediction of Sawdust Pyrolysis Yields from a Flat-Flame Burner Using the CPD Model. Energy Fuels 2013, 27, 942-953.

(28) Niemelä, N. P.; Tolvanen, H.; Saarinen, T.; Leppänen, A.; Joronen, T. CFD based reactivity parameter determination for biomass particles of multiple size ranges in high heating rate devolatilization. Energy 2017, 128, 676-687.

(29) Nunn, T. R.; Howard, J. B.; Longwell, J. P.; Peters, W. A. Product Compositions and Kinetics in the Rapid Pyrolysis of Sweet Gum Hardwood. Ind. Eng. Chem. Process Des. Dev. 1985, 24, 836-844.

(30) Umeki, K.; Kirtania, K.; Chen, L.; Bhattacharya, S. Fuel Particle Conversion of Pulverized Biomass during Pyrolysis in an Entrained Flow Reactor. Ind. Eng. Chem. Res. 2012, 51, 13973-13979. 
(31) Zanzi, R.; Sjöström, K.; Björnbom, E. Rapid high-temperature pyrolysis of biomass in a free-fall reactor. Fuel 1996, 75, 545-550.

(32) Zanzi, R.; Sjöström, K.; Björnbom, E. Rapid pyrolysis of agricultural residues at high temperature. Biomass Bioenergy 2002, 23, 357-366.

(33) Johansen, J. M.; Gadsbøll, R.; Thomsen, J.; Jensen, P. A.; Glarborg, P.; Ek, P.; De Martini, N.; Mancini, M.; Weber, R.; Mitchell, R. E. Devolatilization kinetics of woody biomass at short residence times and high heating rates and peak temperatures. App. Energy 2016, 162, 245-256.

(34) Johansen, J. M. Power Plant Burners for Bio-Dust Combustion. Ph.D. thesis, Department og Chemical amd Biochemical Engineering, DTU, 2015.

(35) Anastasakis, K.; Kitsiou, I.; de Jong, W. Fast devolatilization characteristics of 'low cost' biomass fuels, wood and reed. Potential feedstock for gasification. Fuel Process. Technol. 2016, 142, 157-166.

(36) Asadullah, M.; Zhang, S.; Li, C.-Z. Evaluation of structural features of chars from pyrolysis of biomass of different particle sizes. Fuel Process. Technol. 2010, 91, 877881.

(37) Jiménez, S.; Remacha, P.; Ballesteros, J. C.; Giménez, A.; Ballester, J. Kinetics of devolatilization and oxidation of a pulverized biomass in an entrained flow reactor under realistic combustion conditions. Combust. Flame 2008, 152, 588-603.

(38) Solano, M. L.; Manzanedo, E.; Concheso, R.; Curt, M. D.; Sanz, M.; Ferna, J. Potassium fertilisation and the thermal behaviour of Cynara cardunculus L. Biomass Bioenergy 2010, 4, 1487-1494.

(39) Chen, L.; Dupont, C.; Salvador, S.; Grateau, M.; Boissonnet, G.; Schweich, D. Experi- 
mental study on fast pyrolysis of free-falling millimetric biomass particles between 800 ${ }^{\circ} \mathrm{C}$ and $1000{ }^{\circ} \mathrm{C}$. Fuel 2013, 106, $61-66$.

(40) Dubitzky, W.; Granzow, M.; Berrar, D. P. Fundamentals of Data Mining in Genomics and Proteomics, page 178; Springer US, 2007.

(41) Eskildsen, C. E.; Hansen, P. W.; Skov, T.; Marini, F.; Nørgaard, L. Evaluation of Multivariate Calibration Models Transferred between Spectroscopic Instruments: Applied to near Infrared Measurements of Flour Samples. J. Near Infrared Spectrosc. 2016, 24, $151-156$.

(42) Winning, H. Standardization of FT-IR instruments. White Paper from Foss A/S 2014, $1,1-7$. 